\title{
SHIELDING GAS EFFECT ON THE STRUCTURE OF VARIABLE POLARITY GMA WELDBRAZED JOINTS OF GALVANISED SHEETS
}

\begin{abstract}
The article presents the course and results of tests aimed to determine the effect of shielding gas on the shape of a weldbraze and on the structure of weldbrazed joints made of thin galvanised sheets. Test joints were made using innovative VP GMA weldbrazing utilising variable current and voltage waveforms. The tests involved the use of 3 types of shielding gases and mixtures, i.e. Ar, $\mathrm{Ar}+1 \% \mathrm{O}_{2}$ and $\mathrm{Ar}+18 \% \mathrm{CO}_{2}$, and required macro and microscopic metallographic examination of overlay brazes and weldbrazed joints. The tests conducted have revealed that the use of mixtures containing active gases, and $\mathrm{CO}_{2}$ in particular, increases the heat input of a weldbrazing process, improves the wettability of sheets and the geometry of weldbrazes, yet it also favours greater coat damage in the joining area and causes partial melting of workpieces.

Keywords: arc weldbrazing, variable polarity GMA weldbrazing, weldbrazing of zinc coated sheets, shielding gas effect, weldbraze structure
\end{abstract}

\section{Introduction}

Many industries, such as automotive, see the increasingly common use of coated and uncoated sheets of thicknesses ranging from 0.7 to $3 \mathrm{~mm}$. One of the key groups of technological processes of an advanced car body is welding process of joining metal elements. At present, a dominant and very efficient process used for joining car body elements is resistance spot welding. The major problem accompanying AHSS resistance welding is the occurrence of brittle cracks in the joint plane caused by an increased content of $\mathrm{C}$ and alloying elements. Due to this fact it is possible to observe growing demand for producing high quality joints made of, among others, galvanised steel sheets. The achievement of desirable results requires the use of efficient welding methods ensuring proper weld quality while maintaining the primary anticorrosive properties of a parent metal [1-3].

The use of conventional arc welding methods, such as MIG/ MAG, causes excessive heat input to a joint leading to workpiece deformations. In the case of galvanised sheets MIG/MAG welding is responsible for the evaporation and oxidation of zinc. As a result, the parent metal loses its anticorrosive properties and the joint contains such imperfections as gas pores, cracks, lack of penetration and incomplete fusions. The use of brazing makes it possible to limit the heat input to a material, yet at the same time it fails to provide sufficiently high process efficiency. Sheet deformations and anticorrosive coating damage develop during standard and pulsed arc MIG/MAG weldbrazing commonly used in the automotive industry $[2,4]$. The increased interest in brazing in the industry is the result of low complexity of required changes of the automated workstation, on which the arc welding process has been performed so far.

Weldbrazing methods ensuring the obtainment of high joint quality and aesthetics are so-called low-energy methods, for instance CMT and ColdArc. The use of these methods makes it possible to limit heat input and obtain high joining process stability, which results in smaller deformations and lower damage to protective coating as well as improves joint aesthetics by limiting spatter formation. The latest low-energy solution is based on variable polarity pulsed current used in GMA welding and weldbrazing [5-8]. The latter is usually conducted using Ar-based shielding gas [9]. Currently, it is used pure argon, but because of its neutral character and a low value of thermal conductivity coefficient, there are imperfections of weldbraze shape. However, the analysis of reference publications has led to a conclusion that the use of oxidising gases (argon with oxygen or carbon dioxide additions) improves the wettability and spreadability of the molten filler metal on the parent metal surface as well as increases arc stability, improves weld face appearance and decreases the amount of spatters [1]. Oxygen decrease the surface tension at the interface between deposited metal and base material (improves wettability) and increase the arc voltage, which improves its stability.

The objective of the tests conducted was to determine the effect of a given shielding gas type on the geometry and structure of weldbrazes, damage to zinc coating as well as on the porosity and spatter formation during VP GMA weldbrazing of zinc-coated sheets.

\footnotetext{
INSTITUTE OF WELDING IN GLIWICE, POLAND, 16-18 BŁOGOSŁAWIONEGO CZESŁAWA STR., 44-100 GLIWICE

Corresponding author: Tomasz.Pfeifer@is.gliwice.pl
} 


\section{Material and methods}

The weldbrazing tests were conducted using a station equipped with a DW 300 welding device (produced by Daihen) and a Romat 310 industrial robot (made by Cloos) ensuring the repeatable movement of a welding torch in accordance with an pre-defined programme. The welding device is a cutting edge inverter power supply enabling the use of alternating current and proper adjustment of the Electrode Negative ratio (shortcut: EN ratio, the portion of time when electrode wire is connected to the negative pole) in the welding current and voltage waveforms within the range between 45 and $80 \%$. The technological weldbrazing tests were carried out with a constant EN value of $60 \%$. All the technological tests were carried out using appropriate fixing tooling.

The tooling applied (clamp system) enabled repeatable fixing of weldbrazed test pieces and prevented their deformation during the process. The torch movement was controlled by programmed robot movement sequence including reaching the weldbrazing starting point, carrying out the process at a predefined rate and returning to the starting point.

The parent metal used in the tests was $1.15 \mathrm{~mm}$ thick galvanised steel grade DC04+ZE75/75 according to PNEN10152:2011. This deep-drawing, unalloyed and full killed steel contains maximum ( $\%$ of mass) $0.08 \% \mathrm{C} ; 0.40 \% \mathrm{Mn}$; $0.030 \% \mathrm{P}$ and $0.030 \% \mathrm{~S}$. The nominal thickness of galvanised coating applied on the upper and lower surfaces of sheets amounts to $7.5 \mu \mathrm{m}$. The weldbrazing tests also involved the use of a Bedra-manufactured Bercoweld S3 solid electrode wire with a diameter of $1 \mathrm{~mm}$ (designation CuSi3Mn1 according to PN-EN ISO 24373).

All the weldbrazing tests were conducted using the following shielding gases:

- $\quad \operatorname{argon}(\mathrm{PN}-\mathrm{EN}$ ISO 14175 - I1 - Ar),

- $99 \% \mathrm{Ar}+1 \% \mathrm{O}_{2}$ (PN-EN ISO $\left.14175-\mathrm{M} 13-\mathrm{ArO}-1\right)$,

- $\quad 82 \% \mathrm{Ar}+18 \% \mathrm{CO}_{2}$ (PN-EN ISO $14175-\mathrm{M} 21-\mathrm{ArC}-18$ ).

The first stage of the technological tests included overlay brazing on the surface of the test pieces made of galvanised sheet and making overlap joints using all the shielding gases tested. The tests aimed to determine the effect of a shielding gas type on process stability, regularity and geometry of overlay braze bead (base surface wettability assessment) as well as the aesthetics of the overlay braze face (influence on surface changes and outer imperfections). The parameters of overlay brazing and weldbrazing of overlap joints with various gases are presented in Table 1.

TABLE 1

Overlay brazing and weldbrazing process parameters

\begin{tabular}{|l|c|c|}
\hline \hline & Ovarlay brazing & $\begin{array}{c}\text { Weldbrazing } \\
\text { - lap joint }\end{array}$ \\
\hline Current intensity, A & 65 & 90 \\
\hline Arc voltage, $\mathrm{V}$ & 17 & 19,5 \\
\hline Travelling speed, cm/min & 55 & 55 \\
\hline
\end{tabular}

At the next stage the test pieces were cut in the plane perpendicular to the longitudinal axis of the overlay braze and joint. The purpose of this activity was to obtain further test pieces for macroscopic metallographic examination. In order to reveal their macrostructure the newly obtained test pieces were subjected to grinding and etching in Adler's reagent.

The final stage of the study involved microscopic metallographic examination of the test pieces containing overlay brazes and overlap weldbrazed joints. The purpose of the examination was to determine the effect of the type of shielding gas on the structure of overlay brazes, weldbrazes and HAZ material. The metallographic examination was conducted using a light microscope LEICA MEF4M provided with the system of digital image analysis. The examination included 50 to $500 \times$ magnified observations of the weldbraze and HAZ areas. Scaning electron microscopy and chemical analysis of precipitations was conducted using HITACHI S-4200 microscope equipped with NORAN VOYAGER 3500 X-ray microanalysis system.

\section{Results and discussion}

Figure 1 presents the exemplary face and the opposite side of the test pieces containing overlay brazes as well as the macrostructures of the overlay brazes made using various shielding gases. On this basis it was possible to determine the effect of shielding gas on the properties of overlay brazes.

The tests conducted have demonstrated that the use of the output parameters developed for argon as the shielding gas, in the case of the two other gas mixtures tested, particularly in the case of the $\mathrm{Ar}+18 \% \mathrm{CO}_{2}$ mixture, causes considerable thermal changes, oxidation and even significant evaporation of the zinc layer previously applied on the galvanised test piece surface (Fig. 1). This proves that the mixtures with oxygen and carbon dioxide as gases having a high oxidation index cause the greater heat input to the overlay brazing zone. In addition, the oxidising gases (oxygen, carbon dioxide) accelerate the evaporation of zinc coatings on steel and damage such coatings as well as lead to the formation of impurities on the overlay braze surface and edges. If compared with argon such mixtures improve wetting of the steel sheet with the filler metal as the oxygen contained in the gas mixture and formed due to the decomposition of $\mathrm{CO}_{2}$ reduces the surface tension on the boundary of filler metal - parent metal phases. This is demonstrated by the macrostructures of the overlay welds revealing the transverse spreading of the filler metal over a wider area and by the lower reinforcement height (Fig. 1). However, in the case of these overlay brazes it was possible to observe disadvantageous partial melting of the steel surface in the arc axis.

While comparing the overlap joints made using argon and the $\mathrm{Ar}+1 \% \mathrm{O}_{2}$ and $\mathrm{Ar}+18 \% \mathrm{CO}_{2}$ mixtures it was observed that the use of oxidising mixtures facilitate wetting of workpieces and spreading of the filler metal, yet it causes far greater heat input to the material, which for the same current parameters as those used with argon causes partial melting of the parent metal as deep 


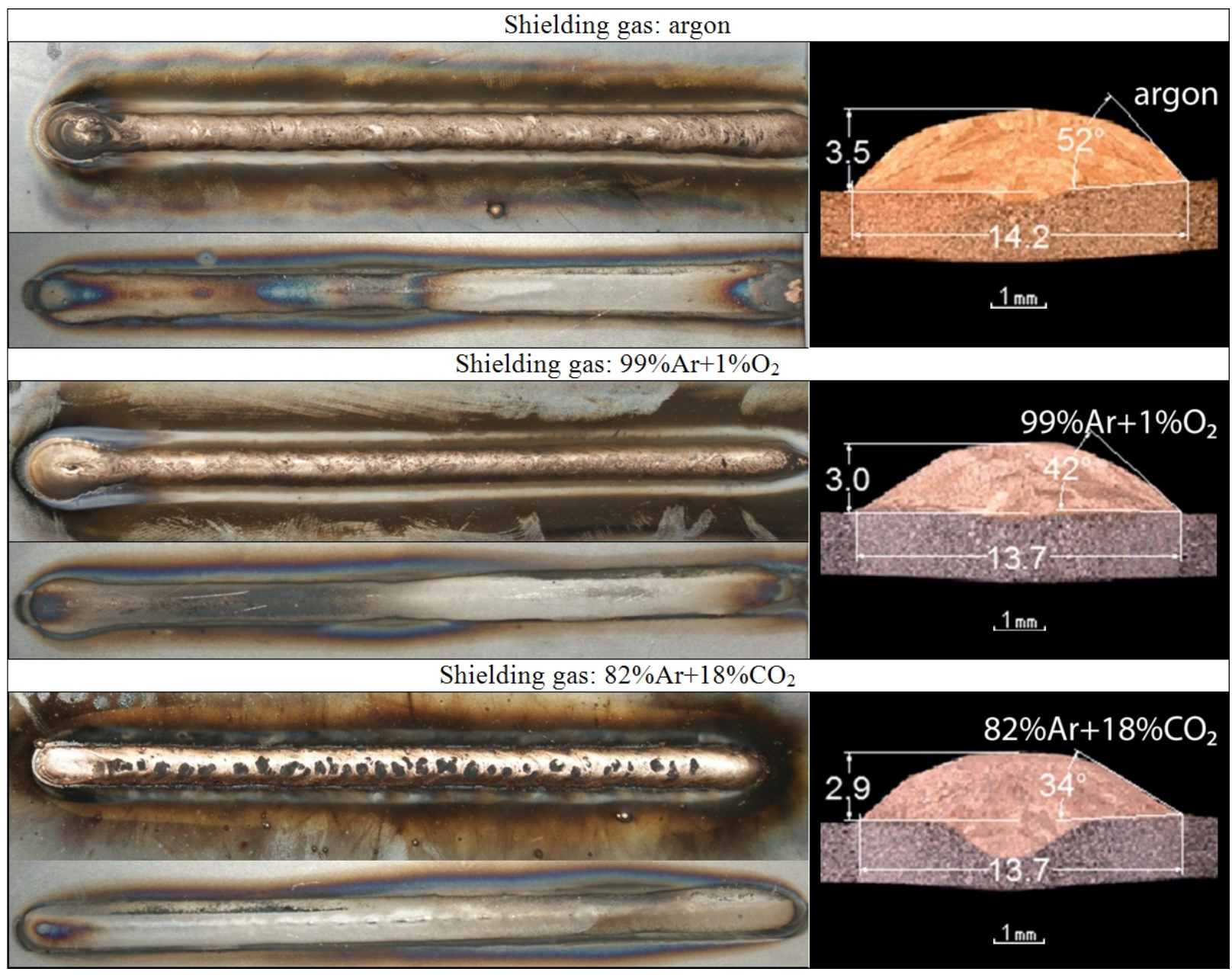

Fig. 1. Overlay brazes made using various shielding gases - view of the face and opposite side of the test piece of the overlay braze, overlay braze macrostructure (etch. Adler)

as approximately 0.5-0.7 $\mathrm{mm}$, or, in extreme cases, may result in the burn-through of the lower sheet of the joint (Fig. 2). The macroscopic metallographic tests have revealed that the use of active gases also causes partial melting of the edge of the upper sheet forming the overlap joint and leads to significantly greater damage to the zinc coating.
The next stage involved the microscopic metallographic examination of the test pieces containing overlay brazes and overlap weldbrazed joints. The purpose of the examination was to determine the effect of the type of shielding gas on the structure of overlay brazes, weldbrazes and HAZ material, as well as on the chemical composition of these areas. The metallographic

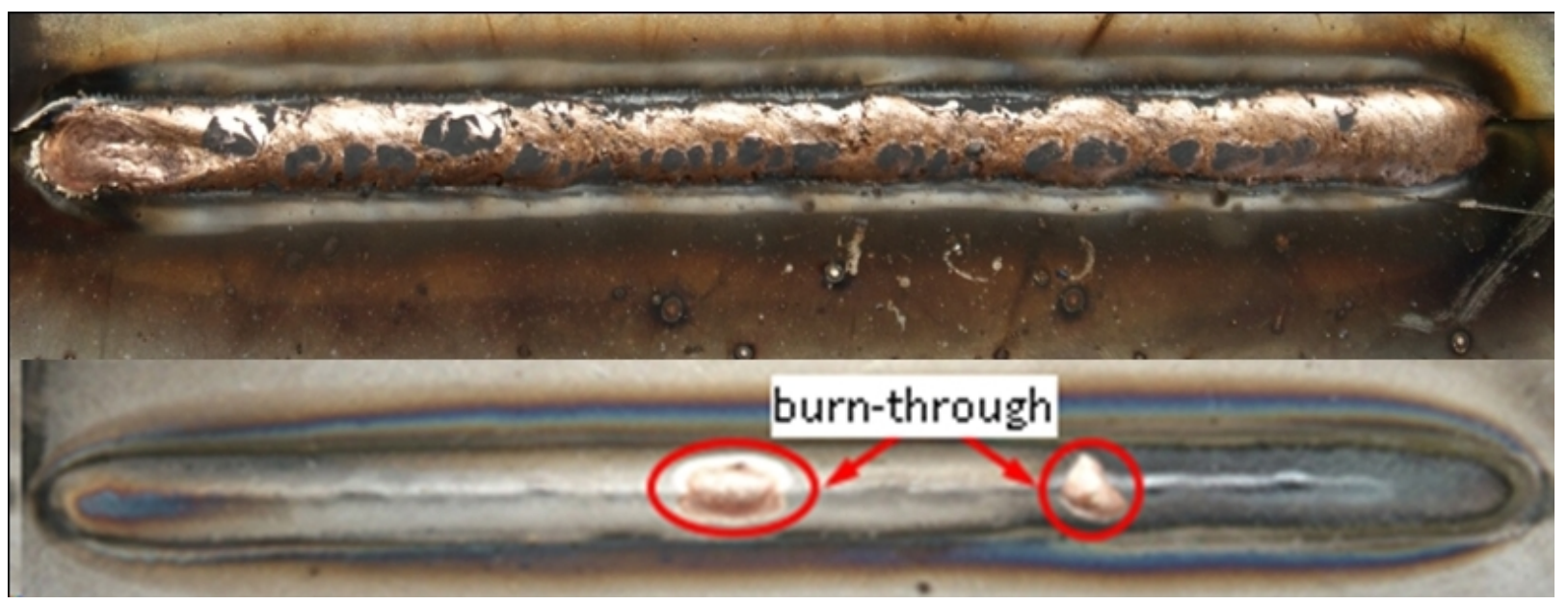

Fig. 2. Overlap joints made using various shielding gases - view of the face and opposite side of the test piece of the weldbrazed lap joints, weldbraze macrostructure (etch. Adler) 
examination was conducted using a light and scanning electron microscope and included 50 to 4000x magnified observations of the weldbraze and HAZ areas. Figures 3-4 present the exemplary digital photographs of the microstructures of overlay brazes and those of weldbrazed joints. All the test pieces underwent etching in iron chloride $\left(\mathrm{FeCl}_{3}\right)$.

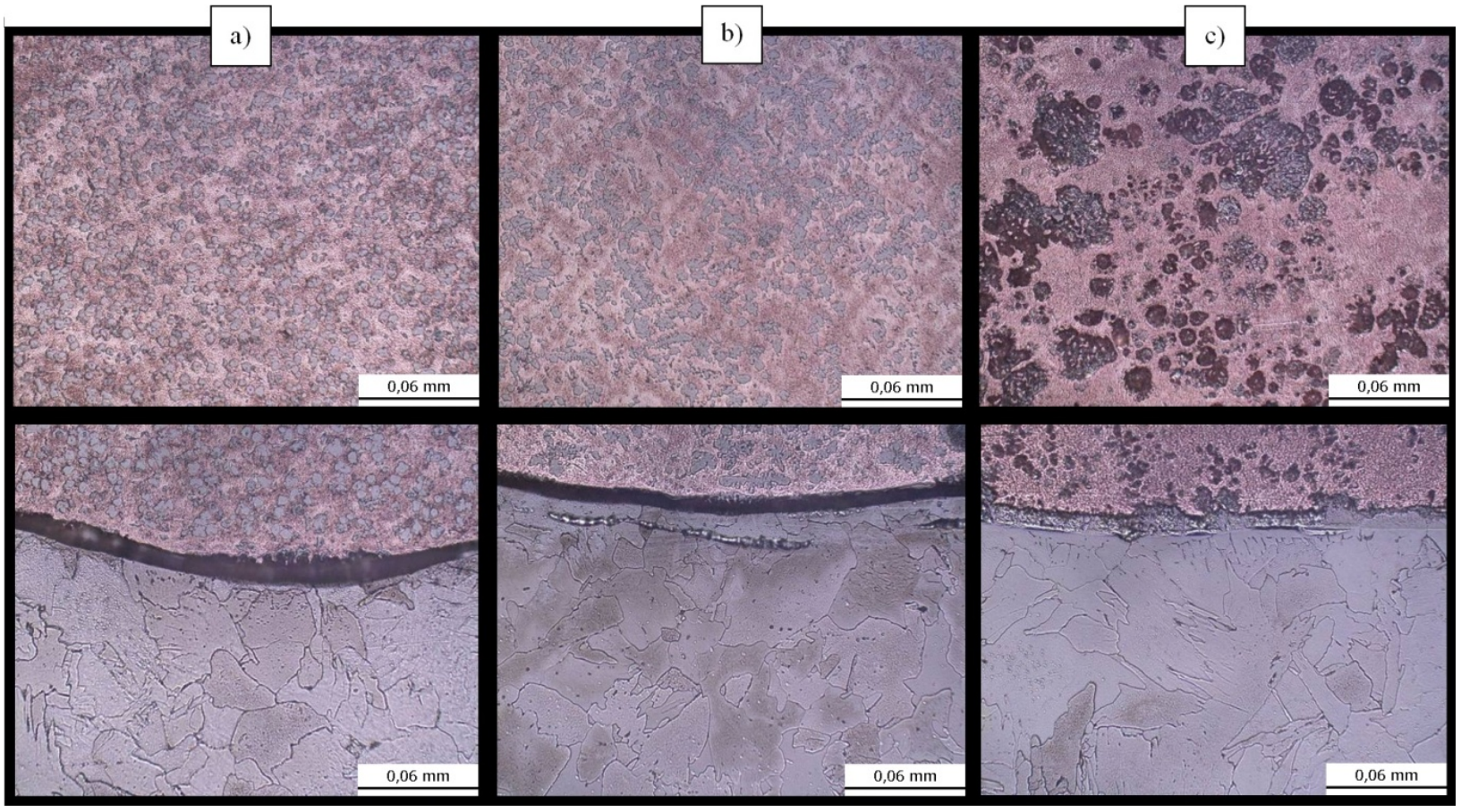

Fig. 3. Microstructure of overlay brazes (upper line) and of the area in the transition area between the overlay braze and the parent metal (lower line), made using $\mathrm{Ar}(\mathrm{a}), \mathrm{Ar}+1 \% \mathrm{O}_{2}$ (b) and $\mathrm{Ar}+18 \% \mathrm{CO}_{2}$ (c), etch. $\mathrm{FeCl}_{3}$

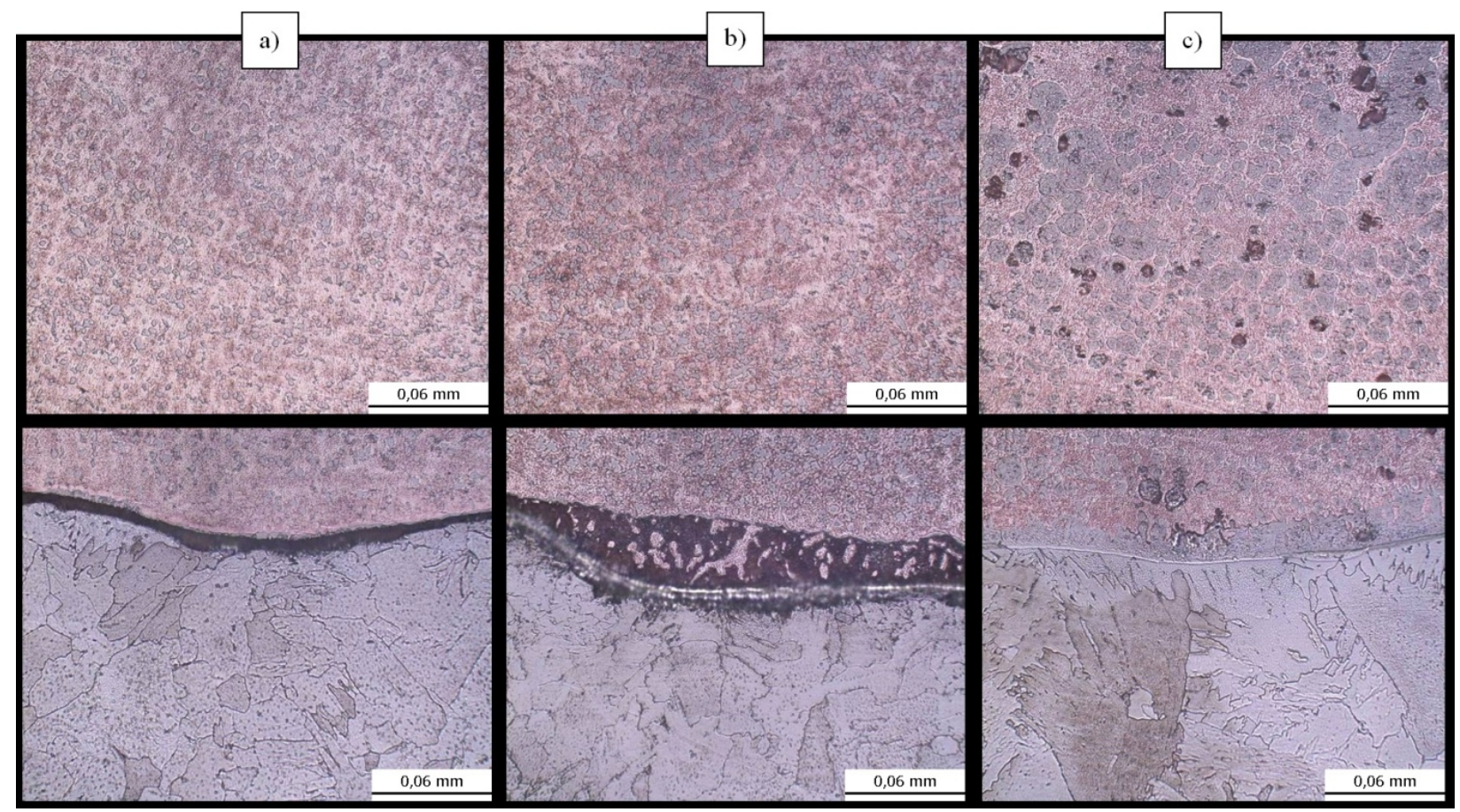

Fig. 4. Microstructure of weldbrazes (upper line) and of the area in the transition area between the weldbraze and the parent metal in the overlap joints (lower line), made using $\mathrm{Ar}(\mathrm{a}), \mathrm{Ar}+1 \% \mathrm{O}_{2}$ (b) and $\mathrm{Ar}+18 \% \mathrm{CO}_{2}$ (c), etch. $\mathrm{FeCl}_{3}$

The microscopic metallographic examination revealed that the structure of the area of overlay brazes and weldbrazes made with argon used as the shielding gas contained bright copper matrix areas $(\alpha)$ which, in turn, contained fine globular precipitates of complex intermetallic phases based on copper and iron
(Fig. 3-5) [4,5,10,11]. The study-related chemical composition tests (X-ray microanalysis) revealed that the structure matrix was the solid solution of $\mathrm{Si}, \mathrm{Mn}$ and $\mathrm{Fe}$ in copper and that the intermetallic phases (dark areas) contained approximately $70 \%$ of $\mathrm{Cu}$ and approximately $15 \%$ of Fe (Fig 6,7). The phases resulted 


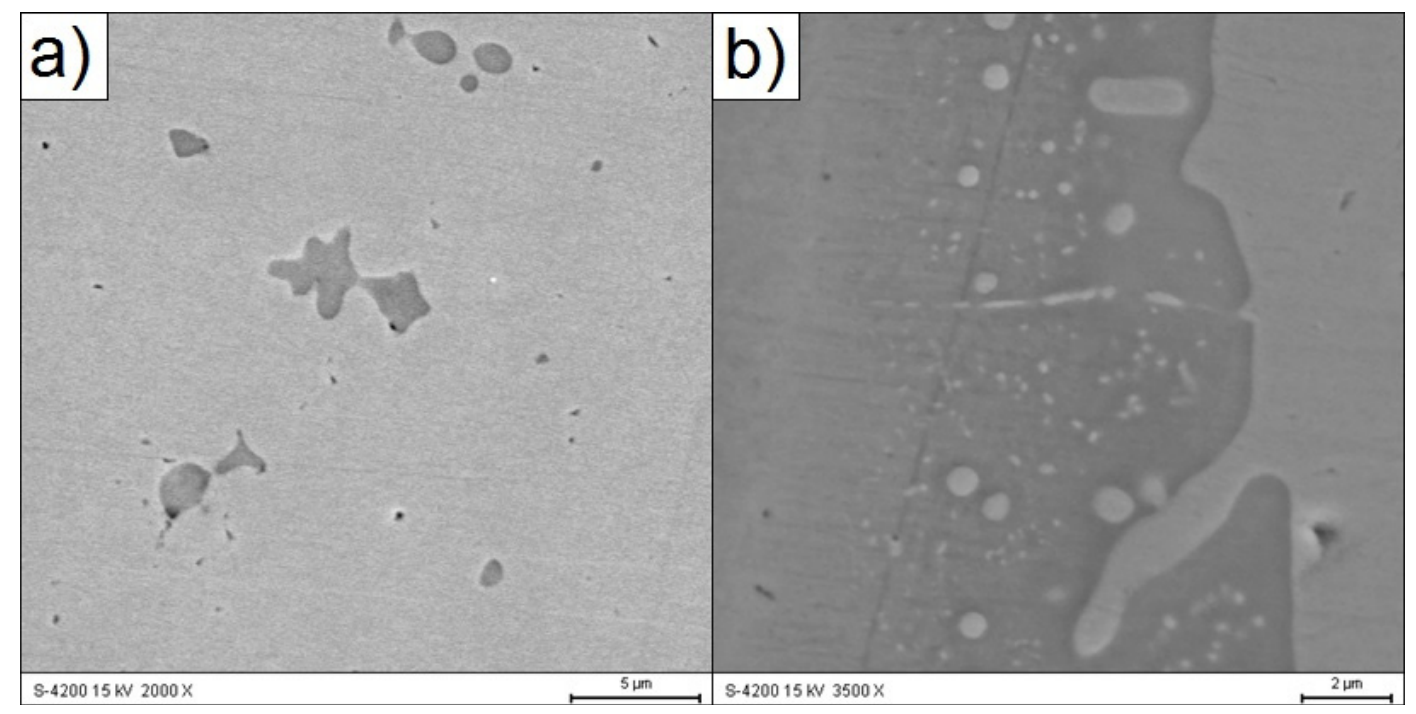

Fig. 5. Microstructure of weldbraze (a) and of the transition area between the weldbraze and the parent metal (b) in the overlap joints made using Ar as shielding gas, SEM

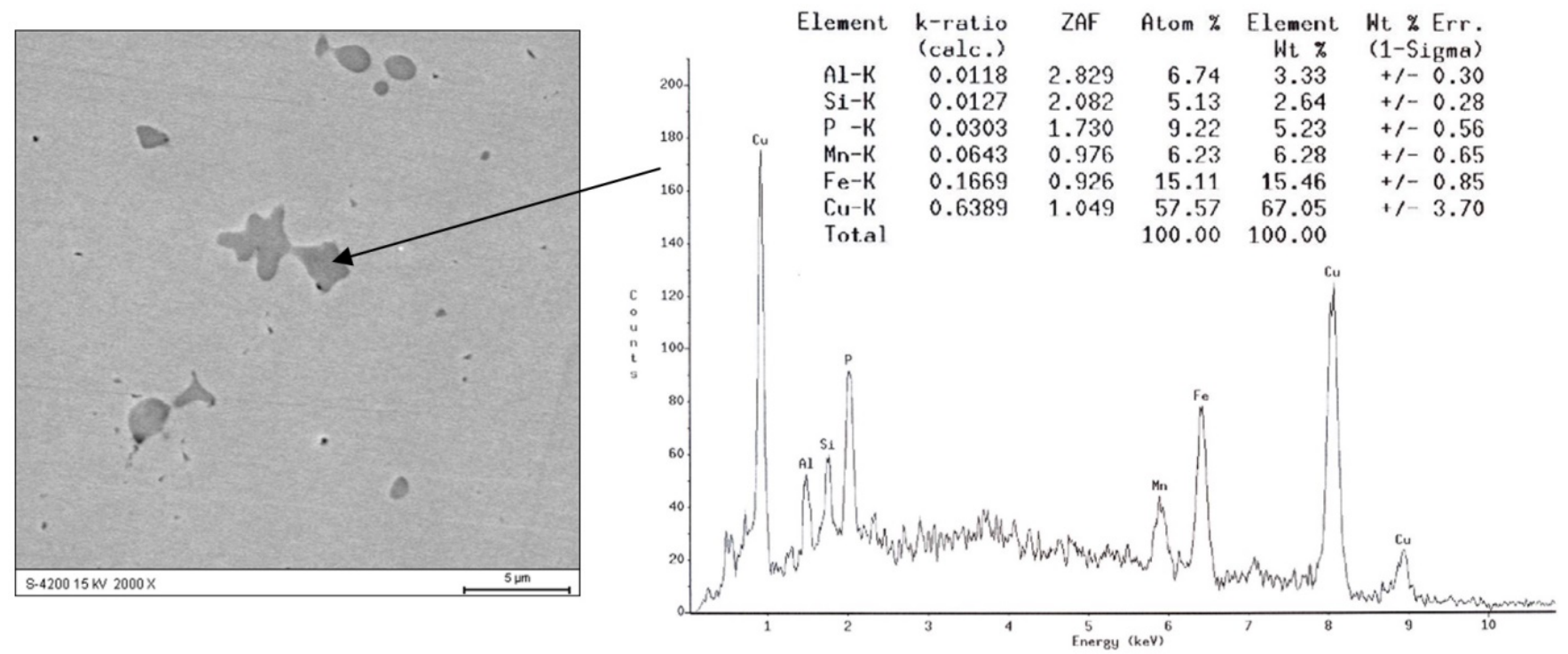

Fig. 6. Results of X-ray microanalysis of chemical composition of precipitation in weldbraze

from dissolving and stirring of the parent metal in the liquid filler metal pool. Linear pattern of elements in the transition area is presented in Fig. 8. This results are confirmed in publications $[4,5]$. The partial melting of the parent metal leading to its intense dissolving in the filler metal is illustrated in the macroscopic photographs of the overlay brazes and overlap joints presented in Figures 1-2.

The structure of the weldbrazes and overlay brazes made using the $\mathrm{Ar}+1 \% \mathrm{O}_{2}$ mixture, analysed in the same area, was similar to the structure obtained while weldbrazing with argon, with the shape of precipitated phases (darker areas) being significantly more complex. In the solid solution matrix it was possible to observe characteristic dendrites. As a rule, the formation of precipitates of dendritic shapes is usually ascribed to the non-uniform thermal conditions during the crystallisation and cooling of the weldbraze material. Introducing $1 \%$ of oxygen to the shielding gas prolonged the overlay braze/weldbraze crystal- lisation time and created the conditions for the crystallisation of dendrites in the direction of the fastest heat off-take.

Overlay brazing and weldbrazing in the $\mathrm{Ar}+18 \% \mathrm{CO}_{2}$ mixture resulted in the obtainment of a structure similar to that received while using argon. However, it was also possible to observe the significant amount of uniformly arranged fine gas pores. Similarly as in the case of argon-shielded overlay brazing and weldbrazing the precipitates of intermetallic phases were globular, yet they formed greater clusters (conglomerates) broken by uniformly arranged gas pores.

In the boundary zone between the parent metal and the weldbraze, in the overlay brazes and overlap and butt weldbrazed joints made using argon and the mixture of argon with $1 \% \mathrm{O}_{2}$ it was possible to observe a zone (characteristic dark hollow) in which the zinc coating had been entirely removed during etching (in the process of preparing the test pieces for metallographic tests) (Fig. 3-4). Directly outside the zone without the coating it 

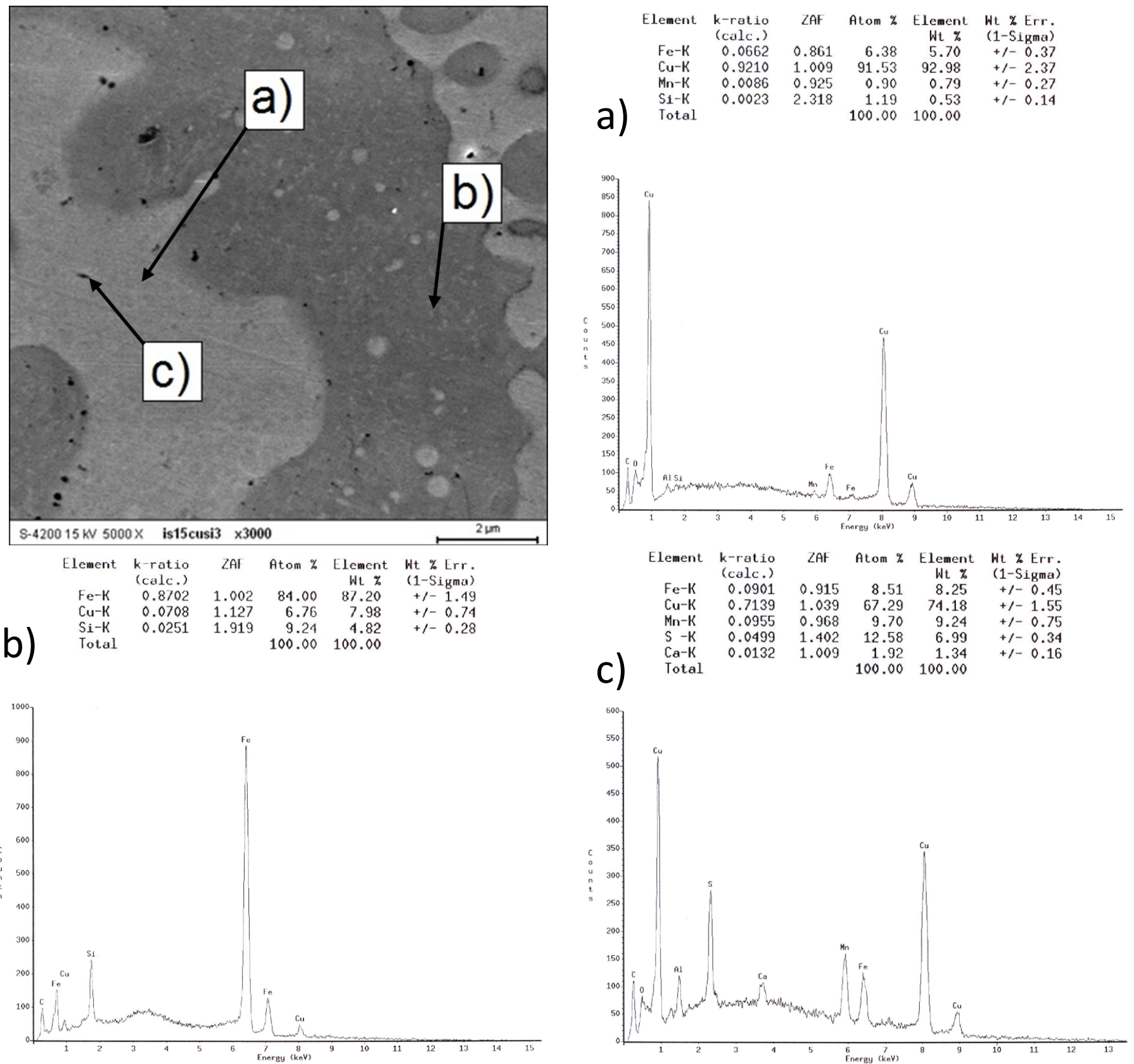

Fig. 7. Results of X-ray microanalysis of chemical composition of precipitation in transition area

was possible to observe the weldbraze structure described above. The microscopic tests of the parent metal revealed the grain growth and recrystallization in the area adjacent to the weldbraze. However, the tests did not show any structural transformations. For comparison, Figure 9 presents the microstructure of the parent metal (a) and the structure of the CuSi3Mn1 electrode wire (filler metal).

The weldbrazed joints and overlay brazes made with the Ar $+18 \% \mathrm{CO}_{2}$ shielding gas mixture contained easily visible transition zones located on the boundary between the parent metal and the weldbraze/overlay braze (Fig. 3c-4c). The structure of this zone was very similar to that presented in the work [4-5]. In this area it was possible to observe the dissolving of the parent metal and the precipitates of intermetallic phases rich in copper and iron, having a varied Fe content ranging from approximately $80 \% \mathrm{Fe}$ to $20 \% \mathrm{Fe}$ in the area adjacent to the weldbraze [4]. The amount and shape of these phases are determined by the type of shielding gas. It can be stated that an increase in the shielding gas oxidation index is accompanied by the formation of greater precipitates having more irregular shapes. These phases are numerous as the parent metal undergoes partial melting, dissolving and stirring in the liquid brazing metal. The formation of these phases can be attributed to the diffusion of the parent metal to the weldbraze. The use of a mixture having a high oxidation index increases the heat input to the metal, which can favour the greater parent metal content in the weldbraze. In turn, the longer time of crystallisation and that of pool cooling can result in the intensification of diffusive phenomena. The greater heat input 


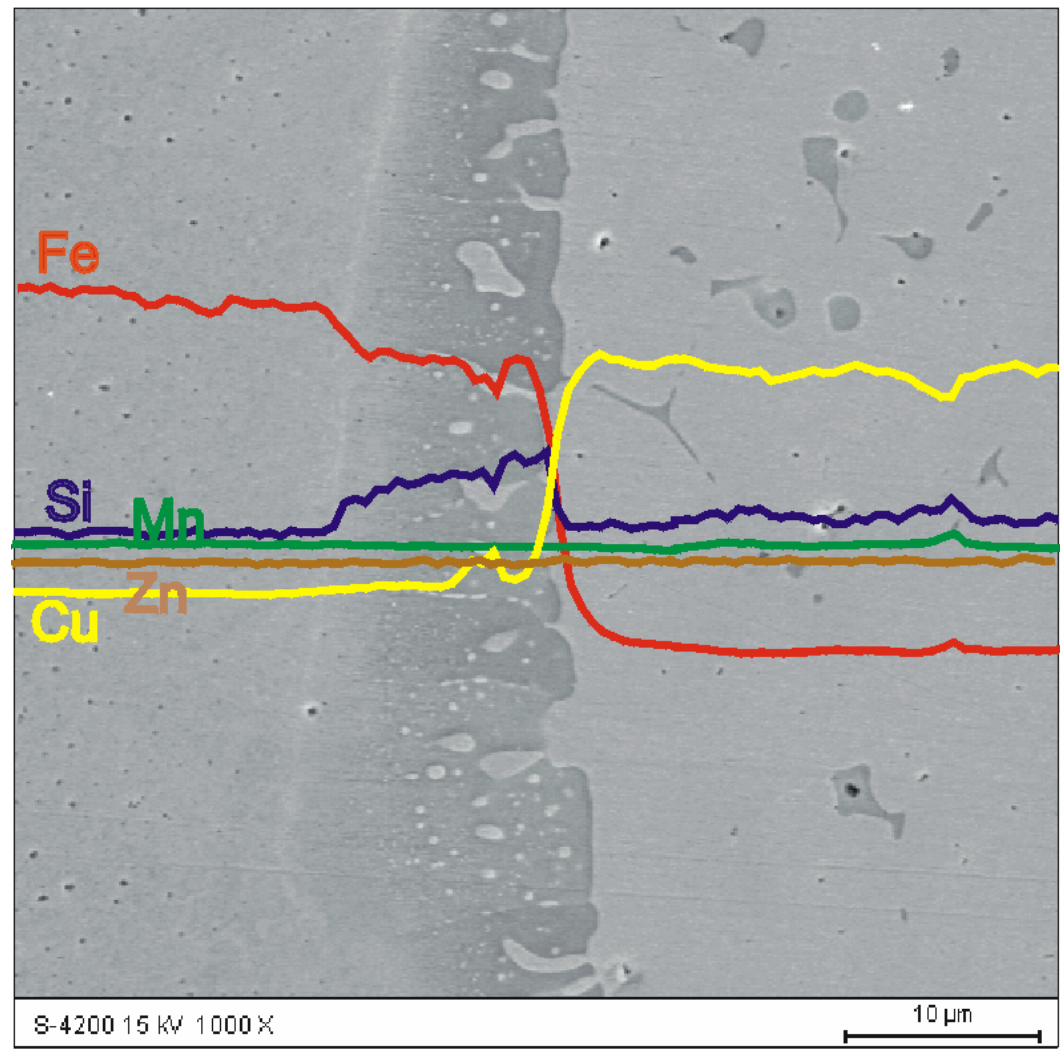

Fig. 8. Linear pattern (distribution) of elements in the transition area
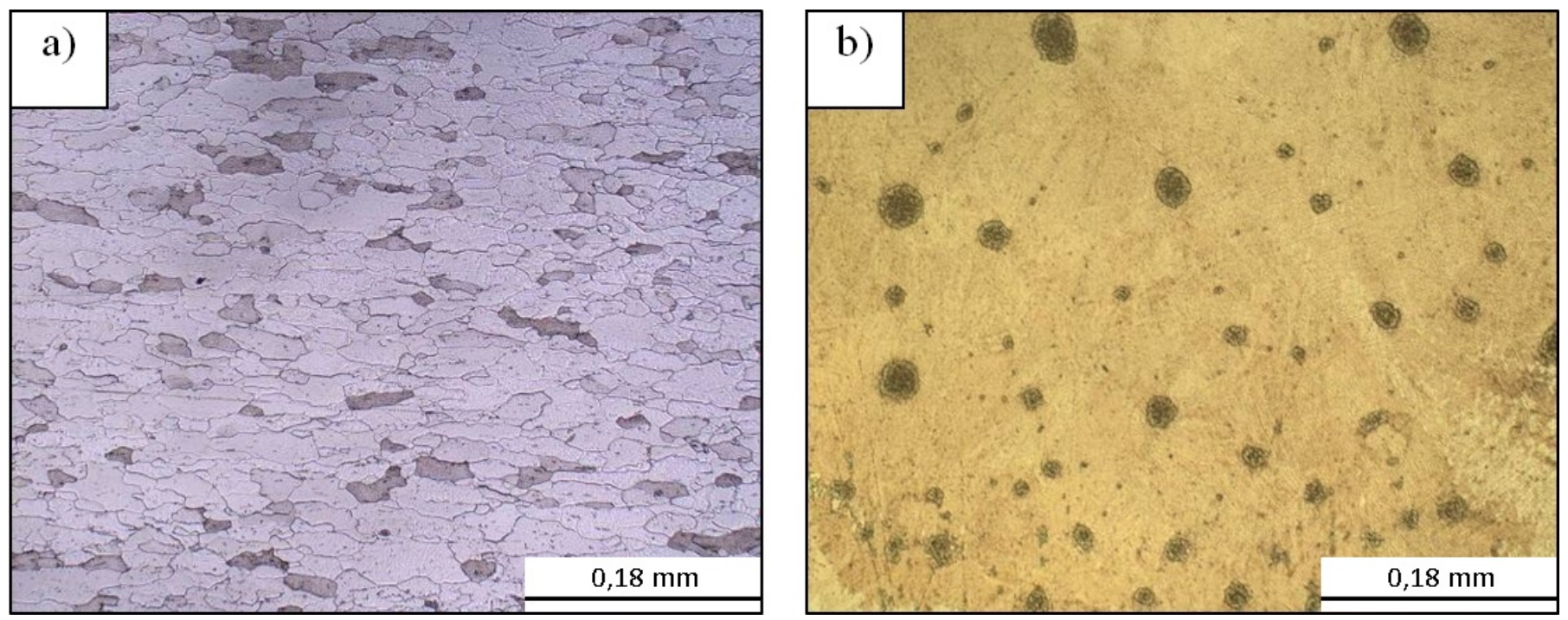

Fig. 9. Microstructure of the DC04 steel parent metal (a) and of the CuSi3Mn1electrode wire (b), etch. $\mathrm{FeCl}_{3}$

to the metal was also demonstrated by the greater grain size in the HAZ, particularly in the case of weldbrazing where argon + $\mathrm{CO}_{2}$ was used as the shielding gas mixture.

\section{Conclusions}

In comparison with argon the use of active $\mathrm{Ar}+1 \% \mathrm{O}_{2}$ and $\mathrm{Ar}+18 \% \mathrm{CO}_{2}$ mixtures significantly improves wetting and enables obtaining weldbrazes having a more convenient shape factor in the case of the solid wire. Such mixtures increase the heat input to joints, which results in the partial melting of the parent metal and its stirring with the liquid brazing metal.

The structure of weldbrazes contains numerous precipitates of copper and iron-based intermetallic phases, the amount and shape of which depend on the type of shielding gas.

The use of active mixtures causes the formation of greater amounts of intermetallic phases in the weldbraze. The greater heat input provides conditions for the crystallisation of precipitates in the form of dendrites. 


\section{REFERENCES}

[1] L. Quintino, G. Pimenta, D. Iordanescu, R. Miranda, N. Pepe, MIG brazing of galvanized thin sheet joints for automotive industry, Materials and Manufacturing Processes 21 (1), 63-73 (2006).

[2] Examining GMA brazing of galvanized steel sheet joints for automotive industry. Brazing and soldering today - technology news, Welding Journal 85 (9), 64 (2006)

[3] A. Grajcar, M. Różański, S. Stano, A. Kowalski, B. Grzegorczyk, Effect of Heat Input on Microstructure and Hardness Distribution of Laser Welded Si-Al TRIP-Type Steel, Advances in Materials Science and Engineering 2014, Article ID 658947, 8 pages, 2014. doi:10.1155/2014/658947.

[4] W. Gawrysiuk, T. Pfeifer, A. Winiowski, Characterization of MIG/ MAG arc weld brazing, Welding Technology Review (2-3), 17-20 (2005).

[5] M. Różański, W. Gawrysiuk, MIG/MAG Braze Welding - galvanized steel sheets and examples of difficult to weld material sets, Welding Technology Review (9), 7-12 (2007).

[6] A. Kiszka, T. Pfeifer, Variable polarity MAG welding of thin protective-coated steel plates, Institute of Welding Bulletin (1), 33-39 (2012).
[7] J. Matusiak, J. Wyciślik, Influence of shielding gas on fume and gas emission during arc weld brazing of steel sheets with coatings. Metalurgija 54 (1), 71-74 (2015).

[8] P. Białucki, A. Ambroziak, W. Derlukiewicz, A. Lange, M. Glezman, Properties of braze welded joints between aluminum and steel, Welding Technology Review 9, 40-44 (2013)

[9] Joseph, C. Webb, M. Harama, D. Yap, Variable polarity improves weld brazing of galvanized sheet, Welding Journal 80 (10), 36-41 (2001).

[10] D. Iordachescu, L. Quintino, R. Miranda, G. Pimenta, Influence of shielding gases and process parameters on metal transfer and bead shape in MIG brazed joints of the thin zinc coated steel plates, Materials and Design 27 (5), 381-390 (2006).

[11] L. Rui-feng, Y. Zhui-shui, Q. Kai, Interfacial structure and joint strengthening in arc brazed galvanized steels with copper based filler, Transactions of Nonferrous Metals Society of China 16 (2), 397-401 (2006). 